\title{
Back-Calculation of Element Tests with a Rate Dependent Soft Soil Model
}

\author{
Jorge Yannie ${ }^{1}$, Nallathamby Sivasithamparam ${ }^{2}$ \\ ${ }^{I}$ Department of Civil and Environmental Engineering, Chalmers University of Technology, Gothenburg, Sweden \\ ${ }^{2}$ Department of Computational Geo-mechanics, Norwegian Geotechnical Institute, Oslo, Norway \\ E-mails: ${ }^{1}$ jorge.yannie@chalmers.se (corresponding author); ${ }^{2}$ nallathamby.siva@ngi.no
}

\begin{abstract}
It is well known that soft clays are geo-materials with properties such as fabric, bonding and rate-dependency. The response observed when modelling complex boundary value problems will depend on the ability of the soil model to capture these features. This paper point out the importance of modelling anisotropy, de-structuration and rate-dependency for normally or slightly over-consolidated clays. In this study, samples from Bothkennar clay (Scotland) were simulated and compared to laboratory data. The constitutive model used in this paper is the recently developed CreepSCLAY1S. The model could predict both qualitative and quantitative the tests results. Selection of the parameters from standard laboratory tests was a key step in the predictions. It was relevant to have different types of laboratory tests to derive a best set of parameters.
\end{abstract}

Keywords: Soft clay, anisotropy, structure, rate dependent, creep, constitutive law, numerical modelling.

Conference topic: Design experiences and theoretical solutions.

\section{Introduction}

A lot of progress has been made in the development of advanced constitutive models for natural soft soils that capture important characteristics such as fabric, bonding and rate-dependency (Wheeler et al. 2003; Leoni et al. 2008; Sivasithamparam et al. 2015). These advance models require additional parameters to capture the additional features that simple elasto-plastic model (e.g. modified Cam-Clay model) are lacking. Determination of these parameters can sometimes be difficult if the engineer does not have a sound understanding of soil behaviour and the advanced constitutive model. In addition, some models parameters do not have any physical meaning and cannot be obtained directly from laboratory tests. Hence, a good constitutive model should be simple and easy to understand without compromising is modelling capabilities. Furthermore, determination of the model key parameters should be possible from standard laboratory tests. Therefore, a recently developed advance constitutive model for soft clays, the Creep-SCLAY1S (Sivasithamparam et al. 2015), is used in this paper to model standard laboratory tests from the anisotropic and structured Bothkennar clay. A short description of the constitutive model, standard laboratory tests and their back-calculation using Creep-SCLAY1S model are presented. For a comprehensive description of the model see Sivasithamparam et al. (2015).

\section{Soil constitutive model}

The soil constitutive model used to back calculate the standard laboratory tests from Bothkennar clay was the rate-dependent Creep-SCLAY1S model (Sivasithamparam et al. 2015; Karstunen et al. 2013). This model is an anisotropic rate-dependent constitutive model that includes destructuration during creep straining for soft soils. The model differs to traditional elasto-plastic model as it does not have a consistency condition to satisfy (i.e. there is no purely elastic domain and a fixed yield criterion for the onset of plastic strains). Therefore, elastic and creep deformation take part at all time within the Normal Consolidation Surface (NCS) as shown in Figure 1. In addition, the stress path can overshoot the NCS depending on the rate of loading (over-stress type model). The creep strains and rate-dependency are given by a generalized empirical formulation derived from one dimensional observations.

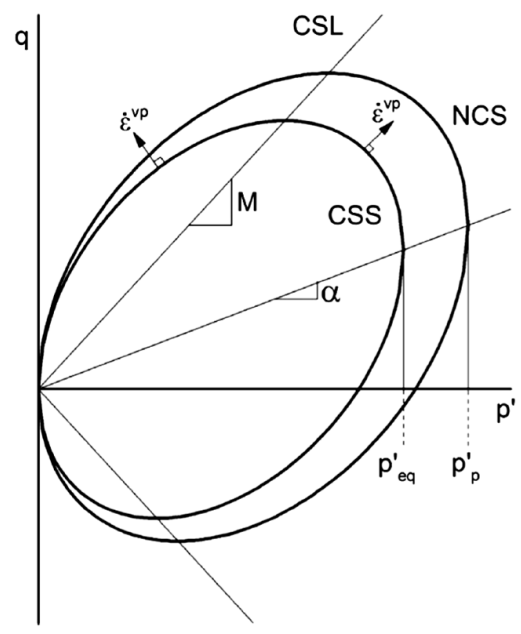

Fig. 1. Distorted and rotated ellipse in q-p' plane representing the Current State Surface (CSS) and Normal Consolidation Surface (NCS) of the Creep-SCLAY1 model (Intrinsic Surface not plotted) (Source: Sivasithamparam et al. 2015) 
Within the Current Stress Surface (CSS) the soil will behave mainly elastic. During loading with a stress path moving the CSS towards NCS, the creep strains will start to become significant. As the stress path crosses through the NCS, large creep strains start to develop. The critical state will be unique in the stress space and independent of stress path and strain rate.

The creep is formulated in the model using the concept of the constant rate of visco-plastic multiplier $(\dot{\Lambda})$ as shown in Eqs (1) to (3).

$$
\begin{gathered}
\dot{\Lambda}=\frac{\mu^{*}}{\tau}\left(\frac{1}{O C R^{*}}\right)^{\beta}\left(\frac{M_{c}^{2}-\alpha^{2} K_{0}{ }^{n c}}{M_{c}^{2}-\eta_{K_{0}{ }^{n c}}^{2}}\right) ; \\
\mu^{*}=\frac{C_{\alpha}}{\ln 10\left(1+e_{0}\right)} ; \\
\beta=\frac{\lambda^{*}-\kappa^{*}}{\mu^{*}},
\end{gathered}
$$

where: $\mu^{*}-$ is referred to as the modified creep index, $\tau$ - is the reference time, $O C R^{*}-$ is the ratio between mean pre-consolidation pressure $p^{\prime}{ }_{p}$ and equivalent current mean stress $p_{e q}^{\prime}, C_{\alpha}$ - is the secondary compression index, $\lambda^{*}$ and $\kappa^{*}$ - are the modified compression and swelling indexes respectively, $M_{c}$ is the stress ratio at critical state under compression loading, $\alpha_{K_{0}^{n c}}-$ the inclination of the ellipses under normally consolidation state, and $\eta_{K_{0}^{n c}}=q / p^{\prime}-$ the actual stress ratio in the 1D normally consolidated stress path.

\section{Laboratory tests and back-calculation: Bothkennar clay}

Bothkennar clay is a well-documented soil that exhibit the properties of soft clays named previously (Institution of Civil Engineers, 1992). This clay was selected to evaluate the Creep-SCLAY1S model capabilities for soft clays. The selected laboratory tests for back-calculation are listed in Table 1.

Table 1. Bothkennar clay laboratory tests for back-calculation

\begin{tabular}{c|c|c|c}
\hline $\begin{array}{c}\text { Depth } \\
(\mathrm{m})\end{array}$ & Test & Rate & Code \\
\hline \multirow{2}{*}{3.8} & $\mathrm{IL}$ & $\Delta \sigma / 24 \mathrm{hr}$ & $6 \mathrm{~B}-1$ \\
\cline { 2 - 4 } & $\mathrm{CRS}$ & $0.0250 \% / \mathrm{min}$ & $6 \mathrm{~B}$ \\
\hline 5.3 & $\mathrm{IL}$ & $\Delta \sigma / 24 \mathrm{hr}$ & - \\
\hline \multirow{2}{*}{$5.3-$} & $\begin{array}{c}\text { Triaxial } \\
\text { extension }\end{array}$ & $1.0 \% /$ day & LCU3 \\
\cline { 2 - 4 } 6.3 & $\begin{array}{c}\text { Triaxial } \\
\text { compression }\end{array}$ & $1.0 \% /$ day & LCU1\&2 \\
\cline { 3 - 4 } & & $4.5 \% /$ day & LCU4, SCU1\&2 \\
\hline \multirow{2}{*}{13.9} & CRS & $0.0750 \% / \mathrm{min}$ & $25 \mathrm{~B}-1 \mathrm{~B}$ \\
\cline { 3 - 4 } & & $0.0025 \% / \mathrm{min}$ & $25 \mathrm{~B}-1 \mathrm{~A}$ \\
\hline
\end{tabular}

To simulate 1D compression experiments, a set of Constant-Rate of Strain (CRS) and Increment Loading (IL) oedometer laboratory test data from 3.8 and $13.9 \mathrm{~m}$ depths were used. For the case of triaxial simulations, laboratory test data from 5.3-6.3 $\mathrm{m}$ depth were selected. The parameters were recalibrated with the help of an IL at $5.3 \mathrm{~m}$ depth to obtain better fit in triaxial modelling. It should be noted that all laboratory test data used to backcalculate were sampled using a Laval sampler (some disturbance as compared to the Sherbrooke block sampler).

In order to back-calculate the IL tests, a finite element model was built using Plaxis (www.plaxis.nl) to account for the excess pore water pressure and consolidation of the clay. The permeability used for all cases was $3 \mathrm{E}-06 \mathrm{~m} / \mathrm{h}$ and the time reference of $24 \mathrm{~h}$. All other simulations were done in the soil test facility available in Plaxis. The model parameters used in the back-calculation are summarized in Table 2.

The back-calculation of CRS and IL oedometer tests using Creep-SCLAY1S is presented in Figure 2 and 3 together with the measured laboratory data. The ratedependent behaviour of Bothkennar clay is clearly shown when comparing the IL and CRS laboratory test data (Figure 2) and the CRS tests with varying strain rate (Figure 3 ). The model was able to predict the rate-dependent behaviour very well in both cases. Furthermore, one simulation was done without the structure $\left(\chi_{0}=0\right)$ in order to show the importance of modelling de-structuration (see Fig. 2, solid line). In addition, the $5.3 \mathrm{~m}$ IL laboratory data and simulation is shown in Figure 2, which is used to optimize the model parameters for triaxial backcalculations.

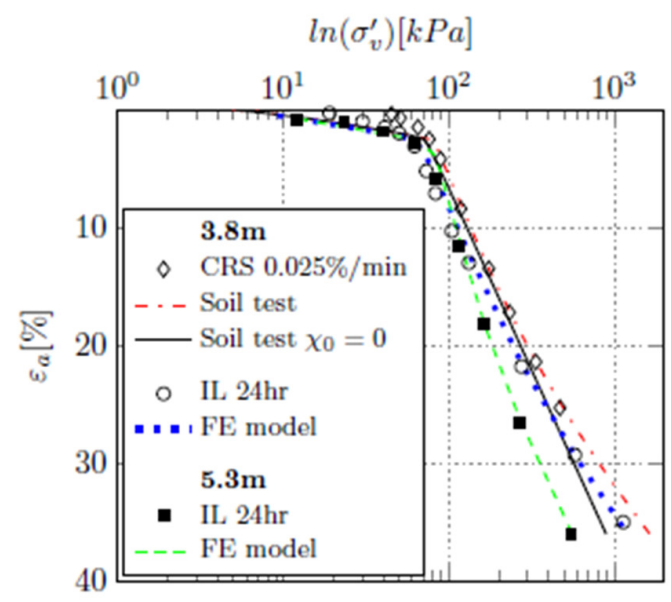

Fig. 2. Test comparing rate-dependency and the effects of de-structuration for 3.8 and $5.3 \mathrm{~m}$

Figure 4 presents yield points from laboratory tests found by Smith et al. (1992) using Laval samples and featuring the corresponding Creep-SCLAY1S yield locus. It also shows triaxial tests for samples depth of 5.3-6.3 $\mathrm{m}$ and their simulations. The theoretical initial 
Table 2. Parameters for the CREEP-SCLAY1S model (Source: Sivasithamparam et al. 2015)

\begin{tabular}{|c|c|c|c|c|c|c|c|c|c|c|c|c|c|c|}
\hline $\mathrm{z}$ & $\kappa^{*}$ & $\lambda \mathrm{i}^{*}$ & $\mu \mathrm{i}^{*}$ & OCR & $\sigma_{0}^{\prime}$ & $v$ & $\mathrm{Mc}$ & $\mathrm{Me}$ & $\omega$ & $\omega \mathrm{d}^{\dagger}$ & $\xi$ & $\xi \mathrm{d}$ & $\alpha 0^{\dagger}$ & $\mathrm{X} 0$ \\
\hline 3.8 & 0.01 & 0.068 & 0.003 & 1.75 & 36 & \multirow{3}{*}{0.2} & \multirow{3}{*}{1.55} & \multirow{3}{*}{1.10} & \multirow{3}{*}{50} & \multirow{3}{*}{0.93} & 10 & 0.2 & \multirow{3}{*}{0.53} & \multirow{3}{*}{12} \\
\hline 5 & 0.01 & 0.085 & 0.003 & 1.74 & 43 & & & & & & 9 & 0.2 & & \\
\hline 13.9 & 0.003 & 0.068 & 0.003 & 1.51 & 96 & & & & & & 9 & 0.2 & & \\
\hline
\end{tabular}

Note: $\uparrow$ Using Jacky's formula for $K_{0}^{n c}$ with $34^{\circ} i=$ intrinsic.

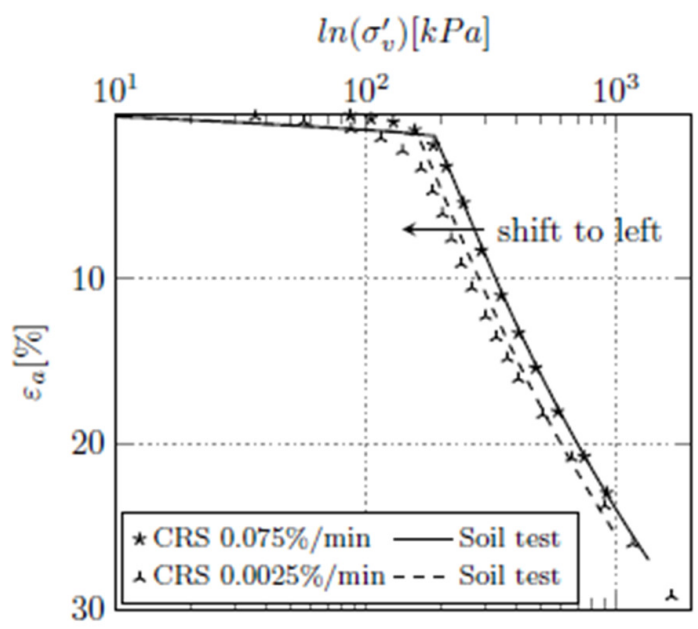

Fig. 3. Test comparing rate-dependency for $13.9 \mathrm{~m}$

yield locus (dashed line, Fig. 4) does not seem to have the same shape as the laboratory points in the extension and dry side. It is important to note that the model is made for normally to slightly over-consolidated clays (i.e. over predicts the dry side). In addition, the evolving anisotropy in the model will rotate the yield surface given a proper fitting in the extension side.

From these simulations, it was judged that $\mathrm{Mc}=$ 1.55 and $\mathrm{Me}=1.10$ fitted well the peak undrained shear strength $(\mathrm{Cu}$ peak). These correspond to a critical state angle of $38^{\circ}$ and $42^{\circ}$ respectively. These values are larger in comparison to critical states angles for reconstitute samples: $34^{\circ}(\mathrm{Mc}=1.38)$ and $37^{\circ}(\mathrm{Me}=1.00)$ as suggested Allman and Atkinson (1992). Furthermore, they are lower than the peaks from high quality block samples: $43.5^{\circ}(\mathrm{Mc}=1.78)$ and $49^{\circ}(\mathrm{Me}=1.20)$. Very large strains are necessary in order to reach critical state as in the reconstitute soils. In practice, these large strains should be avoided. Therefore, focus is set to the peak strength in ultimate limit state (ULS).

Triaxial compression simulations were done using two strain rates (4.5 and $1.0 \% \varepsilon$-axial/day). The model predicts $5.5 \%$ of increased in $\mathrm{Cu}$ for faster loading compared to the slower loading. This is in good agreement with the estimated strength increase of $5-7 \%$ by Smith et al. (1992).

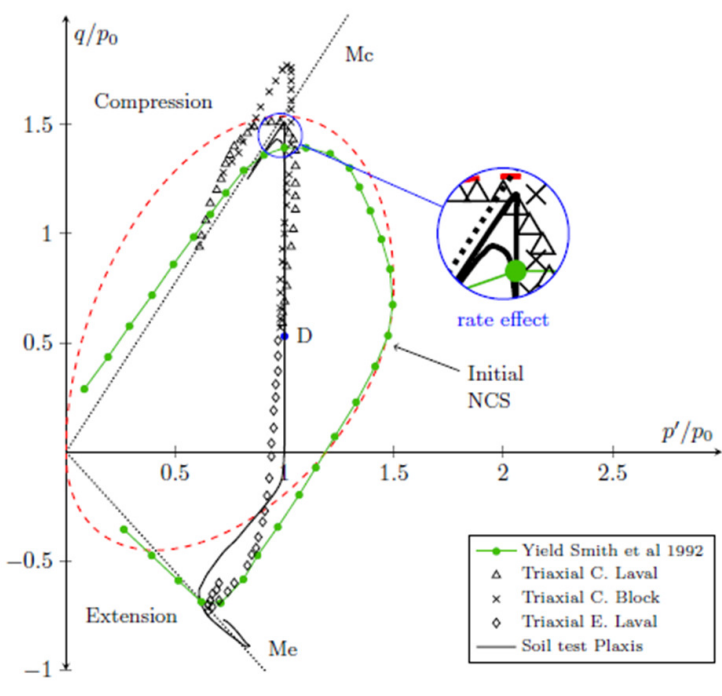

Fig. 4. Triaxial laboratory data and simulation for tests at depth 5.3-6.3 m

One could discuss that the determination of the yield locus is subjective to the interpretation of the yield points. For a soil with evolving anisotropy and different loading stress ratios, the conventional methodologies (e.g. Casagrande's method) may not be appropriate to determine the pre-consolidation pressure. The yield stress (apparent pre-consolidation pressure) showed some scatter in the literature and it can be due to natural variability and sample disturbance. The yield stress may not be a unique point, but rather a range of yielding stresses ( $\mathrm{Si}$ vasithamparam, Castro 2015). Therefore, one should use engineering judgement (under the working stress-strain range) to select yield points and model parameters.

\section{Conclusions}

This paper presents back-calculation of selected Bothkennar clay laboratory tests using the Creep-SCLAY1S model. The model captured natural soil behaviour such as anisotropy, destructuration and rate-dependency. The plot of the yield stresses shows that without a rotated (anisotropic) and distorted ellipse, the model cannot fit the yield points and hence predicts the proper strains. The simulation of CRS test data without destructuration predicts softer behaviour compared to the measured data. The importance of rate-dependent behaviour is also highlighted in the paper using back-calculations of varying 
strain rates. Furthermore, the creep strains were in close agreement to the results from the IL test. From all these results, it can be concluded that better prediction can be achieved by modelling aforementioned characteristics of natural soil behaviour. This is relevant for boundary value problems, where (1) short-term bearing capacity will depend on loading rates and (2) the long-term performance will rely on the settlement prediction.

\section{Acknowledgement}

The research was carried out as part of CREEP (Creep of Geomaterials, PIAP-GA-2011-286397) projects supported by the European Community through the programme Marie Curie Industry-Academia Partnerships and Pathways (IAPP) under the 7th Framework Programme.

\section{Funding}

Funding toward the 1th author as part of the BIG (Branschsamverkan i grunden) project by the Swedish Transport Administration and from the Chalmers research fund (Chalmersska forskningsfonden) is gratefully acknowledged.

\section{References}

Allman, M. A.; Atkinson, J. H. 1992. Mechanical properties of reconstituted Bothkennar soil, Géotechnique 42(2): 289301. http://dx.doi.org/10.1680/geot.1992.42.2.289

Institution of Civil Engineers. 1992. Bothkennar soft clay test site: characterization and lessons learned., Géotechnique 42(2): 161-378.

Karstunen, M.; Sivasithamparam, N.; Brinkgreve, R. B. J.; Bonnier, P. G. 2013. Modelling rate-dependent behaviour of structured clays, in International. Conference on Installation Effects in Geotechnical Engineering, 24-27 March 2013, Rotterdam, 43-50.

Leoni, M.; Karstunen, M.; Vermeer, P. A. 2008. Anisotropic creep model for soft soils, Géotechnique 58(3): 215-226. http://dx.doi.org/10.1680/geot.2008.58.3.215

Sivasithamparam, N.; Karstunen, M.; Bonnier, P. 2015. Modelling creep behaviour of anisotropic soft soils, Computers and Geotechnics 69: 46-57. http://dx.doi.org/10.1016/j.compgeo.2015.04.015

Sivasithamparam, N.; Castro, J. 2015. An anisotropic elastoplastic model for soft clays based on logarithmic contractancy, International Journal for Numerical Analytical Methods in Geomechanics 40: 596-621. http://dx.doi.org/10.1002/nag.2418

Smith, P. R.; Jardine, R. J.; Hight, D. W. 1992. The yielding of Bothkennar clay, Géotechnique 42(2): 257-274. http://dx.doi.org/10.1680/geot.1992.42.2.257

Wheeler, S. J.; Näätänen, A.; Karstunen, M.; Lojander, M. 2003. An anisotropic elastoplastic model for soft clays, Canadian Geotechnical Journal 40(2): 403-418. http://dx.doi.org/10.1139/t02-119 